\title{
Identifikasi Variabel-Variabel yang Mempengaruhi Penentuan Lahan Pertanian Pangan Berkelanjutan di Kabupaten Jombang, Jawa Timur
}

\author{
Gatot Subroto dan Cahyono Susetyo \\ Jurusan Perencanaan Wilayah dan Kota, Fakultas Teknik Sipil dan Perencanaan, \\ Institut Teknologi Sepuluh Nopember (ITS) \\ Jl. Arief Rahman Hakim, Surabaya 60111 Indonesia \\ e-mail: c.susetyo@urplan.its.ac.id
}

\begin{abstract}
Abstrak- Alih fungsi lahan-lahan pertanian subur selama ini kurang diimbangi oleh upaya-upaya terpadu mengembangkan lahan pertanian melalui pemanfaatan lahan marginal. Di sisi lain, alih fungsi lahan pertanian pangan menyebabkan berkurangnya penguasaan lahan sehingga berdampak pada menurunnya pendapatan petani. Oleh karena itu, diperlukan pengendalian laju alih fungsi lahan pertanian pangan melalui perlindungan lahan pertanian pangan untuk mewujudkan ketahanan, kamandirian dan kedaulatan pangan, dalam rangka meningkatkan kesejahteraan petani dan masyarakat pada umumnya.Tujuan dari penelitian ini adalah menentukan peruntukan lahan pertanian pangan berkelanjutan di Kabupaten Jombang. Tujuan tersebut dapat dicapai setelah Menentukan variabel-variabel penentu LP2B di Kabupaten Jombang. Adapun hasil dari penelitian ini menunjukkan bahwa terdapat 11 variabel fisik dan lokasi yang berpengaruh dalam penentuan lahan pertanian pangan berkelanjutan dengan menggunakan metode AHP untuk pembobotan variabelnya.
\end{abstract}

Kata Kunci- alih fungsi lahan, lahan pertanian pangan berkelanjutan, Kabupaten Jombang.

\section{PENDAHULUAN}

【 AHAN pertanian perlu dilindungi agar pasokan $\Lambda_{k e b u t u h a n}$ pangan tetap terjaga. di Indonesia, perlindungan terhadap lahan pertanian tercantum dalam UU No 41 Tahun 2009 tentang Lahan Pertanian Pangan Berkelanjutan. Lahan Pertanian Pangan Berkelanjutan adalah bidang lahan pertanian yang ditetapkan untuk dilindungi dan dikembangkan secara konsisten guna menghasilkan pangan pokok bagi kemandirian, ketahanan, dan kedaulatan pangan nasional. Ketersediaan lahan untuk usaha pertanian merupakan syarat mutlak untuk mewujudkan peran sektor pertanian secara berkelanjutan, terutama dalam perannya mewujudkan kemandirian, ketahanan, dan kedaulatan pangan nasional.

Permasalahan yang dihadapi saat ini adalah tingginya tekanan terhadap lahan. Hal ini disebabkan oleh peningkatan jumlah penduduk yang masih sekitar 1,49 persen per tahun, sementara luas lahan yang ada relatif tetap, produktivitas lahan pertanian pangan mengalami pelandaian (leveling off) serta kompetisi pemanfatan lahan untuk pembangunan, termasuk pemekaran wilayah provinsi dan kabupaten/kota, sehingga ketersediaan lahan untuk memenuhi kecukupan pangan nasional semakin terancam [1]. Rata-rata penguasaan lahan pertanian pangan oleh petani makin sempit disebabkan oleh pewarisan kepemilikan lahan, terjadi juga persaingan yang tidak seimbang dalam penggunaan lahan, terutama antara sektor pertanian dan non-pertanian. Dalam keadaan seperti ini, apabila paradigma dan sudut pandang para pemangku kepentingan dalam perencanaan pemanfaatan ruang hanya terfokus pada nilai ekonomi sewa lahan (land rent economics), maka tidak ada keseimbangan pembangunan pertanian dengan pembangunan sektor lainnya. Keadaan demikian ini akan berpengaruh terhadap penurunan daya dukung lahan dan lingkungan [2]. Simatupang dalam Gatoet Sroe Hardono, dkk. (2004) menjelaskan bahwa alih fungsi lahan pertanian merupakan ancaman serius terhadap ketahanan dan keamanan pangan. Ketahanan pangan adalah kondisi terpenuhinya pangan bagi rumah tangga yang tercermin dari tersedianya pangan yang cukup baik jumlah maupun mutunya aman merata dan terjangkau. Kedaulatan Pangan adalah hak negara dan bangsa yang secara mandiri dapat menentukan kebijakan pangannya, yang menjamin hak atas pangan bagi rakyatnya serta memberikan hak bagi masyarakatnya untuk menentukan sistem pertanian pangan yang sesuai dengan potensi sumber daya local [3]. Alih fungsi lahan sawah menjadi lahan non-pertanian dari tahun 2008 sampai dengan tahun 2012 diperkirakan seluas 110.000 hektar/tahun. Pada tahun 2008 total luas lahan pertanian di Indonesia sebesar 40.031.166 ha, namun pada tahun 2012 luas lahan pertanian di Indonesia hanya sebesar 39.594.536 [4].

Kabupaten Jombang merupakan salah satu kabupaten di Provinsi Jawa Timur dan termasuk dalam wilayah Gerbangkertosusila (GKS) yang memiliki peran dalam menunjang sektor pertanian melalui penataan ruang untuk kegiatan pertanian. Pengembangan pertanian padi diarahkan untuk swasembada beras di Jombang dan menjadikan Jombang sebagai sentra beras di Jawa Timur. Hambatan yang ditemukan dalam pengembangan pertanian di Kabupaten Jombang adalah alih fungsi lahan pertanian ke non pertanian yang cukup besar. Pada tahun 2010 luas lahan pertanian sebesar 50.097,86 hektar, namun pada tahun 2015 luas lahan pertanian hanya mencapai 40.676 [2]. Dalam RTRW tersebut juga menetapkan lahan pertanian tanaman pangan sebagai lahan pertanian berkelanjutan dengan luasan minimal sebesar 31.569,36 Ha. 
Lahan pertanian pangan berkelanjutan di Kabupaten Jombang ini sudah ditetapkan besaran luasnya, namun dalam hal ini diperlukan adanya penentuan variabel dalam upaya menentukan alokasi Lahan Pertanian Pangan Berkelanjutan secara spasial.

\section{METODE PENELITIAN}

\section{A. Metode Pengumpulan Data}

Pengumpulan data yang digunakan dalam penelitian ini adalah metode pengumpulan data primer. Metode pengumpulan data primer dalam penelitian ini dilakukan dengan pengamatan secara langsung (observasi lapangan), wawancara serta kuisioner. Metode ini bertujuan untuk mendapatkan kondisi lingkungan dan perubahan-perubahan yang terjadi dengan melihat dan mendengar fakta yang ada tanpa harus mengambil sampel ataupun dengan sampel.

Tabel 1.

Teknik Pengumpulan Data Primer

\begin{tabular}{clll}
\hline \hline No. & \multicolumn{1}{c}{ Data } & \multicolumn{1}{c}{ Sumber Data } & \multicolumn{1}{c}{ Teknik } \\
\hline 1 & $\begin{array}{l}\text { Kondisi } \\
\text { pemanfaatan } \\
\text { lahan pertanian }\end{array}$ & Wilayah penelitian & Observasi \\
& di Kabupaten & & \\
& Jombang & & \\
2 & Variabel- & Pemerintah & Wawancara \\
& variabel penentu & Swasta Masyarakat & dan \\
& kawasan & & Kuisioner \\
& pertanian & & \\
& pangan & & \\
& berkelanjutan & & \\
\hline \hline
\end{tabular}

\section{B. Metode Analisis}

Metode analisis yang digunakan dalam penelitian ini digambarkan pada bagan alir berikut ini.

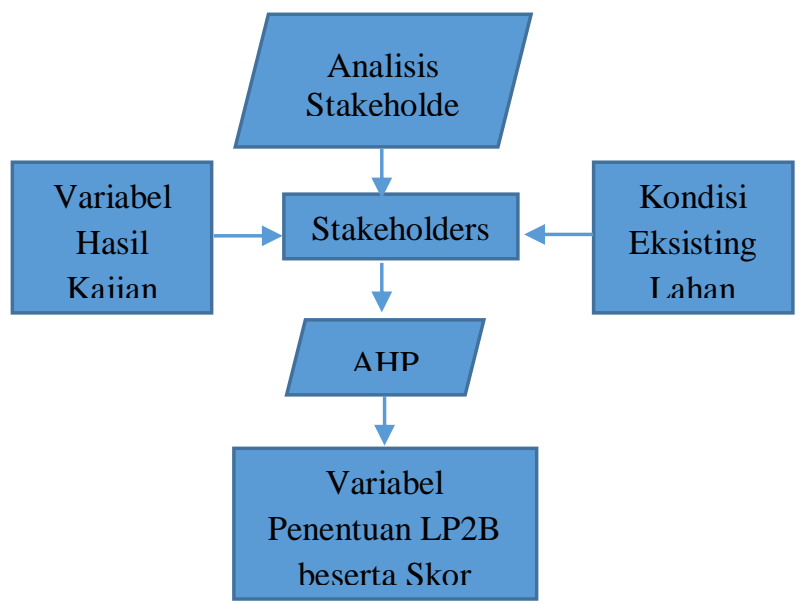

Gambar 1. Metode Analisis

\section{1) Analisis Stakeholders}

Populasi dalam penelitian ini adalah seluruh stakeholders yang memiliki kepentingan dalam penentuan kawasan pertanian berkelanjutan di Kabupaten Jombang. Stakholders yang dimaksud antara lain: a) Pihak Pemerintah

b) Pihak Swasta

c) Pihak Masyarakat (Petani)

Sampel dalam penelitian ini dilakukan dengan menggunakan teknik non probability sampling. Teknik non probability sampling merupakan teknik pengambilan sampel yang tidak memberikan peluang atau kesemaptan yang sama bagi setiap unsur atau anggota populasi untuk dipilih menjadi sampel. Terdapat beberapa teknik yang dapat digunakan dalam non probability sampling, namun dalam penelitian ini penulis menggunakan teknik purposive sampling. Teknik purposive sampling merupakan teknik penentuan sampel dengan pertimbangan data tertentu untuk memperoleh data lebih representatif dengan melakukan proses penelitian yang kompeten pada bidangnya.

2) Analytical Hierarchy Process (AHP)

Analitycal Hierarchy Process atau AHP merupakan suatu model pendukung keputusan yang dikembangkan oleh Thomas L. Saaty. Model pendukung keputusan ini akan menguraikan masalah multi faktor atau multi kriteria yang kompleks menjadi suatu hirarki. Menurut Saaty (1993), hirarki didefinisikan sebagai suatu representasi dari sebuah permasalahan yang kompleks dalam suatu struktur multi level dimana level pertama adalah tujuan, yang diikuti level faktor, kriteria, sub kriteria, dan seterusnya ke bawah hingga level terakhir dari alternatif. Dalam AHP dilakukan konfirmasi terhadap variabelvariabel yang telah ditentukan kepada stakeholder terpilih sekaligus diberikan skor besar pengaruhnya terhadap penentuan lahan pertanian pangan berkelanjutan.

\section{HASIL DAN PEMBAHASAN}

Hasil pertama dalam penelitian ini adalah identifikasi variabel potensial yang dapat digunakan untuk menentukan alokasi LP2B. Untuk mencapai hasil tersebut dilakukan kajian pustaka yang dengan hasil sebagai berikut:

Tabel 2

Kajian Teori Lahan Pertanian Pangan Berkelanjutan

\begin{tabular}{|c|c|c|}
\hline$\overline{\text { No. }}$ & Pakar & Variabel \\
\hline \multirow{5}{*}{1} & Melulosa & Sebaran tingkat produktivitas \\
\hline & Andhytya & sawah \\
\hline & (2013) [5] & Status irigasi lahan sawah \\
\hline & & Intensitas penanaman padi \\
\hline & & $\begin{array}{l}\text { Kesesuaian lahan sawah } \\
\text { Perhitungan kontribusi Ekonomi }\end{array}$ \\
\hline \multirow{5}{*}{2} & Kuswaji & Pertumbuhan ekonomi \\
\hline & Priyono (2010) [6] & Konservasi alam \\
\hline & & Kesehatan lingkungan \\
\hline & & Partisipasi Masyarakat \\
\hline & & Stabilitas Sosial \\
\hline \multirow{3}{*}{3} & $\begin{array}{l}\text { Sasongko } \\
\text { (2013) [7] }\end{array}$ & $\begin{array}{l}\text { Sosial Budaya } \\
\text { Ekonomi }\end{array}$ \\
\hline & & Teknologi Pertanian \\
\hline & & $\begin{array}{l}\text { Kelembagaan } \\
\text { Kebijakan Pemerintah }\end{array}$ \\
\hline \multirow{4}{*}{4} & $\begin{array}{l}\text { Rustiadi dan Reti } \\
\text { (2008) [8] }\end{array}$ & $\begin{array}{l}\text { Potensi sumberdaya } \\
\text { pertanian pangan }\end{array}$ \\
\hline & & Produktivitas lahan \\
\hline & & Fragmentasi lahan pertanian \\
\hline & & $\begin{array}{l}\text { Skala luasan penguasaan lahan } \\
\text { pertanian } \\
\text { Sistem irigasi }\end{array}$ \\
\hline
\end{tabular}




\begin{tabular}{cll}
\hline \hline No. & \multicolumn{1}{c}{ Pakar } & \multicolumn{1}{c}{ Variabel } \\
\hline & & land rent lahan pertanian \\
& & Jenis Tanah \\
& Peraturan & Kesatuan hamparan lahan \\
& Pemerintah Nomor & Potensi teknis dan Kesesuaian \\
5 & 1 Tahun 2011 [9] & Lahan \\
& & Infrastruktur Dasar \\
& Dimanfaatkan sebagai Lahan \\
& Pertanian Pangan \\
\hline \hline Sumber: Hasil Analisis, 2016 &
\end{tabular}

Setelah variabel potensial untuk menentukan alokasi lahan untuk lahan pangan-pertanian berkelanjutan diidentifikasi, langkah selanjutnya dilakukan proses pembobotan. Proses pembobotan variabel dilakukan dengan metode AHP (Analytical Hierarchy Process). Sebelum melakukan proses AHP terlebih dahulu melakukan analisis stakeholders. Analisis ini dilakukan untuk menentukan stakeholder yang memiliki peran dan ahli dalam bidang pertanian pangan. Setelah dilakukan analisis didapatkan 6 stakeholder yang dapat dijadikan responden dalam pemberian bobot pada variabel penelitian. Stakeholders yang terpilih adalah Dinas Pertanian Kabupaten Jombang; Bidang Pertanian Bappeda Kabupaten Jombang; DPU Cipta Karya, Tata Ruang, Kebersihan, dan Pertamanan Kabupaten Jombang, Kementerian Pertanian RI; Akademisi (dosen); Petani. Di bawah ini adalah daftar nama stakeholder yang terpilih:

Tabel 3.

Daftar Nama Stakeholder

\begin{tabular}{cll}
\hline \hline No & \multicolumn{1}{c}{ Nama } & \multicolumn{1}{c}{ Instansi } \\
\hline 1 & Mulyono Sadyohutomo & Akademisi \\
2 & Rudy Ananta & DPU Cipta Karya Tata Ruang \\
3 & Maria Ulfah & Bappeda Kabupaten Jombang \\
4 & Rudi Priono & Dinas Pertanian \\
5 & Paulus Basuki Kuwat S & Kementerian Pertanian \\
6 & Samiadji & Ketua Kelompok Tani \\
\hline \hline
\end{tabular}

Sumber: Analisis, 2016

Setelah diperoleh 6 stakeholder berdasarkan hasil analisis, selanjutnya dilakukan pembagian kuisioner kepada 6 stakeholder tersebut. Dari enam stakeholder menunjukkan bobot dari masing-masing variabel untuk penentuan lahan yang potensial pertanian pangan berkelanjutan. Setelah itu dilakukan proses validasi data dengan melakukan pemeriksaan nilai inkonsistensi pada hasil perhitungan. Setelah diketahui nilai inkonsistensinya kurang dari 0.1 maka dilakukan proses kombinasi. Proses kombinasi ini dilakukan untuk mengetahui bobot setiap variable dari perhitungan bobot masing-masing stakeholder. Adapun kombinasi pembobotan dari keenam stakeholder tersebut dapat dilihat dalam matriks di bawah ini:

Tabel 4.

Matriks Indikator

\begin{tabular}{lccc}
\hline \hline & $\begin{array}{l}\text { Kemampuan } \\
\text { Lahan }\end{array}$ & $\begin{array}{l}\text { Infrastruktur } \\
\text { Dasar }\end{array}$ & Produktivitas \\
\hline $\begin{array}{l}\text { Kemampuan } \\
\text { Lahan }\end{array}$ & 1 & $2 / 1$ & $1 / 2.7$ \\
$\begin{array}{l}\text { Infrastruktur } \\
\begin{array}{l}\text { Dasar } \\
\text { Produktivitas }\end{array}\end{array}$ & $2 / 1$ & 1 & $1 / 2 / 7$ \\
\hline \hline
\end{tabular}

Nilai inkonsistensi $=0.05$
Dari tabel diatas diketahui nilai inkonsistensinya adalah kurang dari 0.1 yaitu 0.05 , sehingga dapat disimpulkan bobot yang diberikan setiap stakeholder adalah valid.

Tabel 5.

Matriks Kriteria Berdasarkan Kemampuan Lahan

\begin{tabular}{lcccccc}
\hline & $\begin{array}{l}\text { Topog- } \\
\text { rafi }\end{array}$ & $\begin{array}{l}\text { Jenis } \\
\text { Tanah }\end{array}$ & $\begin{array}{l}\text { Rawan } \\
\text { Bencana }\end{array}$ & $\begin{array}{l}\text { Curah } \\
\text { hujan }\end{array}$ & $\begin{array}{l}\text { Kelere- } \\
\text { ngan }\end{array}$ & $\begin{array}{l}\text { Keting- } \\
\text { gian }\end{array}$ \\
\hline Topografi & 1 & $1 / 2.5$ & $1 / 1,1$ & $1 / 1.8$ & $1 / 1.9$ & $1.5 / 1$ \\
Jenis Tanah & $2.5 / 1$ & 1 & $1.3 / 1$ & $1 / 1.1$ & $1.6 / 1$ & $3 / 1$ \\
Rawan & $1.1 / 1$ & $1 / 1.3$ & 1 & $1 / 1.4$ & $1.8 / 1$ & $2.1 / 1$ \\
Bencana & & & & & & \\
Curah hujan & $1.8 / 1$ & $1.1 / 1$ & $1.4 / 1$ & 1 & $1.5 / 1$ & $1.9 / 1$ \\
Kelerengan & $1.9 / 1$ & $1 / 1.6$ & $1 / 1.8$ & $1 / 1.5$ & 1 & $1.2 / 1$ \\
Ketinggian & $1 / 1.5$ & $1 / 3$ & $1 / 2.1$ & $1 / 1.9$ & $1 / 1.2$ & 1 \\
\hline \hline
\end{tabular}

Tabel 6.

Matriks Kriteria Berdasarkan Infrastruktur Dasar

\begin{tabular}{ccc}
\hline \hline & Sistem Irigasi & Akses Jalan \\
\hline Sistem Irigasi & 1 & $5.8 / 1$ \\
Akses Jalan & $1 / 5.8$ & 1 \\
\hline Nilai inkonsistensi $=0.00$ & &
\end{tabular}

Tabel 7.

Matriks Kriteria Berdasarkan Produktivitas

\begin{tabular}{lccc}
\hline \hline & Hamparan & Intensitas & Ketersediaan \\
& Lahan & Penanaman & Air \\
\hline Hamparan Lahan & 1 & $1 / 3.1$ & $1 / 6.2$ \\
Intensitas Penanaman & $3.1 / 1$ & 1 & $1 / 1.5$ \\
Ketersediaan Air & $6.2 / 1$ & $1.5 / 1$ & 1 \\
\hline \hline
\end{tabular}

Nilai inkonsistensi $=0.00$

Dari tabel-tabel di atas dapat terlihat bahwa kriteria dengan bobot tertinggi adalah produktivitas dengan bobot 0,573, sedangkan untuk masing-masing variabel diperoleh bobot seperti pada tabel di bawah ini.

Tabel 8.

Bobot Variabel

\begin{tabular}{llc}
\hline \hline No. & Kriteria/Variabel & Bobot \\
\hline Kemampuan Lahan & 0.262 \\
1 & Topografi & 0.117 \\
2 & Jenis Tanah & 0.243 \\
3 & Rawan Bencana & 0.180 \\
4 & Curah Hujan & 0.225 \\
5 & Kelerengan & 0.145 \\
6 & Ketinggian & 0.091 \\
Total & & 1 \\
Infratruktur Dasar & 0.165 \\
1 & Sistem Irigasi & 0.854 \\
2 & Akses Jalan & 0.146 \\
Total & & 1 \\
Produktivitas & 0.573 \\
1 & Hamparan Lahan & 0.104 \\
2 & Intensitas Penanaman & 0.347 \\
3 & Ketersediaan Air & 0.549 \\
Total & & 1 \\
\hline Sumber: Analisis, 2016 &
\end{tabular}

Dari tabel di atas dapat diurutkan berdasarkan prioritas atau bobot dari yang tertinggi sampai terendah. Berikut adalah urutan variabel prioritas penentu lahan pertanian pangan berkelanjutan di Jombang:

Tabel 9.

Priority Variabel 


\begin{tabular}{llc}
\hline \hline No & Kriteria/Variabel & Bobot \\
\hline Produktivitas & 0.573 \\
Kemampuan Lahan & 0.262 \\
Infrastruktur Dasar & 0.165 \\
1 & Sistem Irigasi & 0.854 \\
2 & Ketersediaan Air & 0.549 \\
3 & Intensitas Penanaman & 0.347 \\
4 & Jenis Tanah & 0.243 \\
5 & Curah Hujan & 0.225 \\
6 & Rawan Bencana & 0.180 \\
7 & Akses Jalan & 0.146 \\
8 & Kelerengan & 0.145 \\
9 & Topografi & 0.117 \\
10 & Hamparan Lahan & 0.104 \\
11 & Ketinggian & 0.091 \\
\hline
\end{tabular}

Dalam analisis lahan potensial metode yang digunakan adalah metode overlay menggunakan weight sum dengan kalsifikasi variabel yang telah diatur dalam [5] Peraturan Kementerian Pertanian RI Nomor 79 Tahun 2013 tentang Pedoman Kesesuaian Lahan pada Komoditas Tanaman Pangan. Dalam peraturan ini telah disajikan kriteria kesesuaian lahan untuk komoditas tanaman pangan padi sawah irigasi. Dalam hal ini dibagi menjadi empat kelas, yaitu

1) S1 (sangat sesuai) yaitu lahan tidak memiliki faktor pembatas yang berarti atau nyata terhadap penggunaan secara berkelanjutan, atau faktor pembatas yang bersifat tidak dominan dan tidak akan mereduksi produktifitas lahan secara nyata, diasumsikan dengan nilai 3.

2) S2 (cukup sesuai) yaitu lahan mempunyai faktor pembatas, dan faktor pembatas ini akan berpengaruh terhadap produktifitasnya, memerlukan tambahan masukan (input). Pembatas tersebut biasanya dapat diatasi oleh petani sendiri, diasumsikan dengan nilai 2.

3) S3 (sesuai marginal) yaitu lahan mempunyai faktor pembatas yang dominan, dan factor pembatas ini akan berpengaruh terhadap produktifitasnya, memerlukan tambahan masukan yang lebih banyak daripada lahan yang tergolong S2. Untuk mengatasi faktor pembatas pada S3 memerlukan modal tinggi, sehingga perlu adanya bantuan kepada petani untuk mengatasinya, diasumsikan dengan nilai 1.

4) $\mathrm{N}$ (tidak sesuai) yaitu lahan yang tidak sesuai $(\mathrm{N})$ karena mempunyai factor pembatas yang sangat dominan dan/atau sulit diatasi, diasumsikan dengan nilai 0 .

Kriteria klasifikasi kesesuaian lahan sawah padi sebagaimana tercantum dalam tabel dibawah ini:

Tabel 10.

Kriteria Kesesuaian Lahan yang telah diusahakan untuk Komoditas Tanaman Pangan Padi Sawah Irigasi (Oryza sativa).

\begin{tabular}{|c|c|c|c|c|}
\hline \multirow{2}{*}{$\begin{array}{l}\text { Karakteristik } \\
\text { Lahan }\end{array}$} & \multicolumn{3}{|c|}{ Kelas Kesesuaian Lahan } & \multirow[b]{2}{*}{$\mathrm{N}$} \\
\hline & S1 & S2 & S3 & \\
\hline Ketersediaan Air & Irigasi & Irigasi & Irigasi & - \\
\hline Sistem Irigasi & Teknis & $\begin{array}{l}\text { Semi- } \\
\text { Teknis }\end{array}$ & Tadah Hujan & - \\
\hline Topografi & Daratan & $\begin{array}{l}\text { Bergelom } \\
\text { b-ang }\end{array}$ & Berbukit & - \\
\hline Ketinggian & $0-100$ & $100-500$ & $500-1000$ & $>1000$ \\
\hline Curah Hujan & $>2000$ & $\begin{array}{l}1500 \\
2000\end{array}$ & $1000-1500$ & $<1000$ \\
\hline Kelerengan & $0-2 \%$ & $2-5 \%$ & $5-15 \%$ & $>15 \%$ \\
\hline
\end{tabular}

\begin{tabular}{|c|c|c|c|c|}
\hline \multicolumn{2}{|l|}{ Erosi } & \multirow[t]{2}{*}{$\begin{array}{l}\text { Sangat } \\
\text { ringan }\end{array}$} & Ringan-sedang & $\begin{array}{l}\text { Berat- } \\
\text { sangat } \\
\text { berat }\end{array}$ \\
\hline Banjir & & & $25 \mathrm{~cm},<7$ hari & $\begin{array}{l}>25 \mathrm{~cm}, \\
>7 \text { hari }\end{array}$ \\
\hline $\begin{array}{l}\text { Kesatuan } \\
\text { Hamparan }\end{array}$ & $>5$ ha & - & $<5$ ha & - \\
\hline $\begin{array}{l}\text { Intensitas } \\
\text { Penanaman }\end{array}$ & $3 x$ padi & 2x padi & 1x padi & - \\
\hline
\end{tabular}

Dalam klasifikasi variabel dapat dilakukan penambahan variabel yang tidak terdapat di peraturan menteri pertanian. Sehingga dalam proses klasifikasi harus menyesuaikan dengan peraturan menteri pertanian tersebut. Yaitu empat range, yaitu S1 (sangat sesuai), S2 (cukup sesuai), S3 (sesuai-marginal), serta $\mathrm{N}$ (tidak sesuai).

\section{KESIMPULAN/RINGKASAN}

Berdasarkan hasil dari keseluruhan proses terkait tujuan utama penelitian, maka dapat ditarik kesimpulan sebagai berikut:

1) Berdasarkan penelitian yang telah dilakukan, variabelvariabel yang mempengaruhi penentuan lahan pertanian pangan berkelanjutan di Jombang terdiri dari topografi, jenis tanah, rawan bencana, curah hujan, kelerengan, ketinggian, sistem irigasi, akses jalan, kesatuan hamparan lahan, ketersediaan air, dan produktivitas. Dari 11 variabel, yang memiliki pengaruh tertinggi adalah variabel produktivitas.

2) Dari analisis AHP didapatkan bobot masing-masing variabel penentu lahan pertanian pangan berkelanjutan di Kabupaten Jombang. Bobot factor terbesar adalah factor produktivitas dengan nilai 0.573 , sedangkan bobot terbesar untuk variabel adalah sistem irigasi dengan nilai sebesar 0.854 .

\section{UCAPAN TERIMA KASIH}

Penulis G.S. mengucapkan terima kasih kepada Cahyono Susetyo, ST., M.Sc., Ph.D., selaku dosen pembimbing serta Nursakti Adhi Pratomoatmojo, ST., MSc. yang telah turut membuka wawasan penulis hingga mampu menyelesaikan penelitian ini hingga akhir. Terima kasih disampaikan kepada berbagai pihak terkait yang telah membantu terutama kepada Direktorat Pendidikan Tinggi, Departemen Pendidikan dan Kebudayaan Republik Indonesia yang telah diterimanya dalam kegiatan Program Kreativitas Mahasiswa Bidang Penelitian 2015 sebagai salah satu kegiatan pengembangan penelitian ini.

\section{DAFTAR PUSTAKA}

[1] Pasandaran, Efendi. 2006. Alternatif Kebijakan Pengendalian Konvesi Lahan Sawah Beririgasi di Indonesia. Bogor: Pusat Analisa Sosial Ekonomi dan Kebijakan Pertanian.

[2] Agus, Fahmuddin.,dan Irawan. (2004) Alih Guna dan Aspek Lingkungan Lahan Sawah. dalam Tanah Sawah dan Teknologi Pengelolaannya. Pusat Penelitian dan Pengembangan Tanah dan Agroklimat, Badan Litbang Pertanian.

[3] Gatoet Sroe Hardono, dkk. 2004. Prospek Ketahanan Pangan Nasional. Bogor: Pusat Analisa Sosial Ekonomi dan Kebijakan Pertanian. 
[4] Badan Pusat Statistik Kabupaten Jombang. 2016. Jombang Dalam Angka 2011-2015.

[5] Andhytya, Melulosa. (2009). Kajian Pemetaan Lahan Pertanian Pangan Berkelanjutan (Lp2b) di Kabupaten Purworejo. Universitas Gajah Mada. Jogjakarta.

[6] Priyono. Kuswaji, dkk. (2011) Model Perubahan Penggunaan Lahan Menggunakan Cellular Automata-Markov Chain di Kawasan Mamminasata. Program Studi Geografika Universitas Hasanuddin.

[7] Putra, Sasongko, Purwanto, Kismartini. 2013. Perencanaan pertanian berkelanjutan di Kecamatan Selo.Prosiding Seminar Nasional Pengelolaan Sumberdaya Alam dan Lingkungan. 33-40

[8] Rustiadi, E dan W. Reti.2008. Urgensi Lahan Pertanian pangan Abadi dalam Perspektif Ketahanan Pangan, dalam Arsyad,S dan E. Rustiadi (Ed), Penyelamatan tanah, Air dan Lingkungan. Crestpent Press dan Yayasan Obor Indonesia .p 61-86

[9] PP 1/2011 tentang Penetapan Dan Alih Fungsi Lahan Pertanian Pangan Berkelanjutan 